\title{
Thermal acclimation of photosynthesis and respiration in Eucalyptus pauciflora of varying growth temperatures in Kosciuszko National Park
}

\author{
Caitlin McLeod, Cynthia Turnbull, Gregory Gauthier-Coles, You \\ Zhou, Ainsley Maurer, Ray Zhang, Tanja Cobden, Yvonne Yong
}

\section{Abstract}

The processes of photosynthesis and respiration in plants are largely responsible for levels of atmospheric $\mathrm{CO}_{2}$ globally. Predicting future output and uptake of carbon by plants is therefore crucial for developing accurate climate change models. The effect of temperature acclimation on photosynthesis and respiration rates in plants is currently not considered in global carbon models. Therefore, current terrestrial carbon models may be overestimating carbon release from plants as acclimation to higher growth temperatures in many species leads to a fall in respiration and an increase in the temperature at which photosynthesis is optimised. In this study, the ability of photosynthesis and respiration in snow gums (Eucalyptus pauciflora) to acclimate was tested. Leaf samples were taken from trees at four different elevations, and rates of photosynthesis and respiration were measured at $25^{\circ} \mathrm{C}$ using a licor 6400 Gas Exchange System. Temperatures of each collection site (growth temperatures) were measured hourly over three days using temperature and humidity data loggers (ibuttons). Results were analysed by comparing growth temperature of the samples to the rate of respiration and photosynthesis at $25^{\circ} \mathrm{C}$. Lower temperatures correlated to low rates of photosynthesis and higher rates of respiration, when measured at the common temperature of $25^{\circ} \mathrm{C}$. These results indicate that respiration and photosynthesis in snow gums does acclimate to ambient temperature, and this allows for the development of more accurate climate change models. 


\section{Introduction}

Respiration is the cellular process of the breakdown of energy stores to produce carbon for structural purposes, useable energy (ATP) and reducing agents (NADH) (Atkin and Tjoelker 2003). This process is necessary for the growth and maintenance of tissues and produces $\mathrm{CO}_{2}$ as a by-product (Amthor 2000). Photosynthesis is the production of sugars from $\mathrm{CO}_{2}$ and water, which can then be used in respiration. Both of these processes are undergone due to the functioning of many enzymatic processes, and these are temperature sensitive (Cooper 2000). Therefore, the efficiency of respiration and photosynthesis is dependent on how far the ambient air temperature is from the optimal functioning temperature of the leaf.

Atmospheric carbon dioxide levels have increased by nearly a third since the industrial revolution and are continuing to increase, and are responsible for much of the present and future planet warming. Currently, plants release about 60 gigatonnes of carbon into the atmosphere annually through respiration, which equates to approximately 50 per cent of all $\mathrm{CO}_{2}$ released globally (King et al. 2006; Atkin and Tjoelker 2003). Plants also fix about two-thirds more carbon during photosynthesis than is released during respiration (Atkin et al. 2000).

The rates at which plants photosynthesise and respire therefore heavily affects the accuracy of climate change models. Understanding plant responses to increases in temperature that are inevitable due to climate change is necessary for predicting rates of photosynthesis and respiration in plants in the future. Having a better understanding of this effect will improve the accuracy of current climate change models.

There is evidence that there is acclimation (the process of changing to survive in environments of different temperatures (Stillman 2003)) of both photosynthesis and respiration to increases in temperature in some plant functional types, including woody plants (Liang et al. 2013). Forested area, of which woody plants are the dominant plant functional type, covered approximately 35 per cent of the earth's land surface area in 1997 (current figures are unknown) and thus contribute a very large proportion to the net carbon release and uptake due to plant respiration and photosynthesis (Hansen et al. 2010; Curtis and Wang 1998). Therefore, due to their ability to acclimate, it can be predicted that there would be no change in release or fixation of $\mathrm{CO}_{2}$ in woody plants as a result of a future warmer climate. 
Snow gums (Eucalyptus pauciflora) are a dominant plant species in the Australian Alps and exist over a large area of south-eastern Australia. These trees exist over a range of elevations and temperatures but originate from the same gene pool (Slayter and Morrow 1977). Therefore, if snow gum leaf samples from different locations exhibit different responses when placed under identical conditions, they have changed in response to their environment, and thus acclimation has occurred.

The aim of this study was to determine if acclimation of respiration and photosynthesis occurs in the snow gums of the Australian Alps. It was hypothesised that samples from warmer environments would undergo respiration at a slower rate than samples from colder environments, and that respiration would increase with decreasing growth temperature when tested at $25^{\circ} \mathrm{C}$. It was also hypothesised that samples from warmer environments would photosynthesise at a greater rate than colder environments and that rate of photosynthesis would decrease with decreasing growth temperature when tested at $25^{\circ} \mathrm{C}$.

\section{Materials and method}

\section{Collection}

Samples were collected at four different sites in the Kosciuszko National Park: Lake Jindabyne, elevation $900 \mathrm{~m} \pm 30 \mathrm{~m}$; Kosciuszko information centre, elevation $1,220 \mathrm{~m} \pm 30 \mathrm{~m} ; 50 \mathrm{~m}$ along walking track to Rainbow Lake, elevation 1,620 m $\pm 30 \mathrm{~m}$; Charlotte Pass, elevation 1,830 m $\pm 30 \mathrm{~m}$. Samples were selected from three healthy, mature, north-facing snow gums. A north-facing branch with at least one fully mature and damagefree (disease, insect or otherwise) leaf was cut and placed in a bucket of water. The end was then recut underwater to prevent embolisms. The time that the branches were cut was recorded. A temperature and humidity ibutton was attached to each tree within $5 \mathrm{~cm}$ of the sample cut. Samples were transported back to the lab immediately and placed near a window in the sun to allow photosynthesis to continue.

\section{Analysis}

In the lab, the largest healthy leaf from each branch was labelled and placed in a Licor 6400 Gas Exchange System and tested under photosynthetic conditions (conditions: Block T: $25^{\circ} \mathrm{C}$; $\mathrm{CO}_{2} \mathrm{R}: 400 \mathrm{ppm}$; PAR: 1,500 $\mu \mathrm{mol}$ 
$\mathrm{m}^{-2} \mathrm{~s}^{-1}$; humidity: around 60 per cent). Rates of photosynthesis (amount of $\mathrm{CO}_{2}$ uptake/area of leaf/second) were recorded when readings were steady. Foil was then placed over the leaf for a minimum of 30 minutes. Leaves were then measured again using the Licor under respiration conditions (Block T: $25^{\circ} \mathrm{C} ; \mathrm{CO}_{2} \mathrm{R}: 400$ ppm; PAR: 0; humidity: around 60 per cent). As with photosynthesis, rates of respiration were recorded when readings were steady.

Dry leaf mass (used to convert rates of respiration and photosynthesis from an area basis to a mass basis to account for leaf thickness) were measured by cutting a $2 \mathrm{~cm} \times 3 \mathrm{~cm}$ rectangle (size of the Licor cuvette) out of the centre of the leaf. The rectangle was placed in an envelope and this was put between two sheets of cardboard and microwaved (microwave brand: Tiffany) three times on medium/low power for 2 minutes. The sample was weighed and placed in a bag with silica gel to prevent hydration. The weight was used to convert photosynthetic and respiration readings from the Licor from $\mu \mathrm{mol} \mathrm{CO} \mathrm{m}^{-2} \mathrm{~s}^{-1}$ to $\mathrm{nmol} \mathrm{CO} \mathrm{g}^{-1} \mathrm{~s}^{-1}$.

The ibuttons were removed three days after being attached to the sampled tree. Temperature and humidity recordings were taken once per hour over 48 hours. The average of these readings were calculated and used as the 'growth temperature' for each site. These averages were considered representations of the actual growth temperatures of the samples and they exhibited the relationship between elevation and temperature according to Hopkin's Bioclimatic law (which is used to predict how much colder higher elevations will be than lower elevations at a given latitude).

\section{Results}

Both the day and night air temperature decreased with elevation over the 48-hour period of sampling for the four sample sites (Figure 1). The average of temperatures taken hourly over a 48-hour period in the environment where the sample was taken was used as the growth temperature for each elevation. Growth temperatures were Jindabyne $28.59^{\circ} \mathrm{C}$, Kosciuszko Information Centre $16.48^{\circ} \mathrm{C}$, Rainbow Lake walking track $14.88^{\circ} \mathrm{C}$, Charlotte Pass $14.12^{\circ} \mathrm{C}$. 


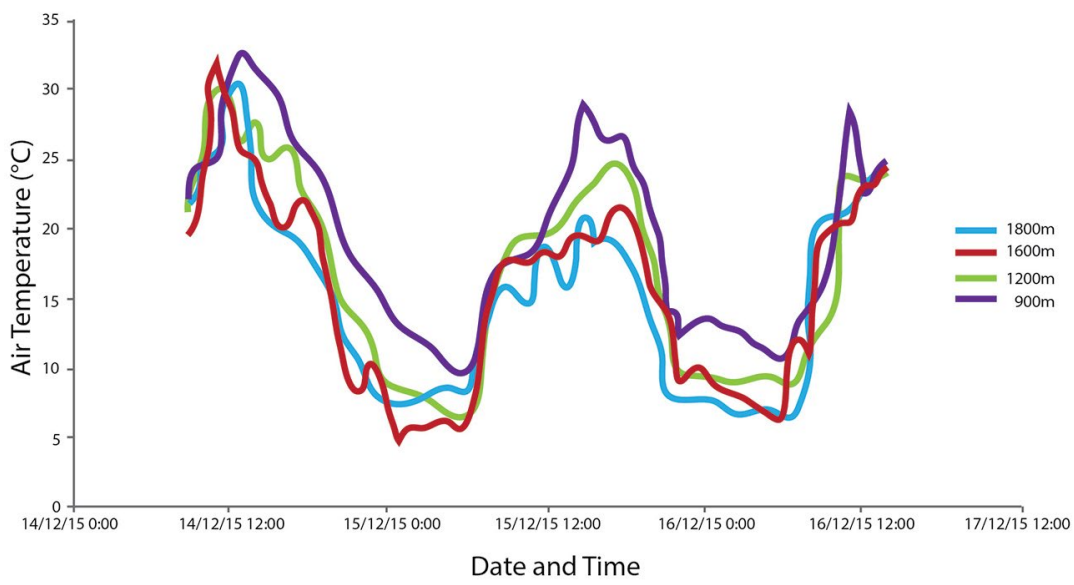

Figure 1: Air temperature over a 48-hour period for each of the sample collection sites, measured using temperature data loggers, recording once per hour.

Source: Authors' data.

When tested at $25^{\circ} \mathrm{C}$, the rate of respiration in E. pauciflora with growth temperature: $28.59^{\circ} \mathrm{C}$ was $3.39 \pm 0.645 \mu \mathrm{mol} \mathrm{m}^{-2} \mathrm{~s}^{-1} ; 16.48^{\circ} \mathrm{C}, 2.85 \pm$ $0.422 \mu \mathrm{mol} \mathrm{m}^{-2} \mathrm{~s}^{-1} ; 14.88^{\circ} \mathrm{C}, 5.67 \pm 0.330 \mu \mathrm{mol} \mathrm{m}^{-2} \mathrm{~s}^{-1}$; and $14.12^{\circ} \mathrm{C}, 5.02$ $\pm 2.88 \mu \mathrm{mol} \mathrm{m}^{-2} \mathrm{~s}^{-1}$. Overall, there was an increase in the rate of respiration as growth temperature increased (Figure 2a).

When tested at $25^{\circ} \mathrm{C}$, the rate of photosynthesis in E. pauciflora with growth temperature: $28.59^{\circ} \mathrm{C}$ was $20.9 \pm 2.69 \mu \mathrm{mol} \mathrm{m}^{-2} \mathrm{~s}^{-1} ; 16.48^{\circ} \mathrm{C}, 21.4$ $\pm 1.88 \mu \mathrm{mol} \mathrm{m}^{-2} \mathrm{~s}^{-1} ; 14.88^{\circ} \mathrm{C}, 16.4 \pm 2.25 \mu \mathrm{mol} \mathrm{m}^{-2} \mathrm{~s}^{-1}$; and $14.12^{\circ} \mathrm{C}, 15.0$ $\pm 2.72 \mu \mathrm{mol} \mathrm{m}^{-2} \mathrm{~s}^{-1}$. Overall, there was a decrease in rate of photosynthesis as growth temperature increased (Figure $2 \mathrm{a}$ ).

The increase in photosynthesis and decline in respiration with growth temperature when measured at the common $25^{\circ} \mathrm{C}$, leads to a decline in respiration as a fraction of photosynthesis with increasing temperature (Figure 2c). Hence, with increasing growth temperature, E. pauciflora is able to retain more carbon per unit of leaf area.

There was no discernible trend between leaf mass per area (LMA) and temperature, with all sites having similar LMA, except Rainbow Lake at $14.22^{\circ} \mathrm{C}$, which had a lower LMA. 
a)

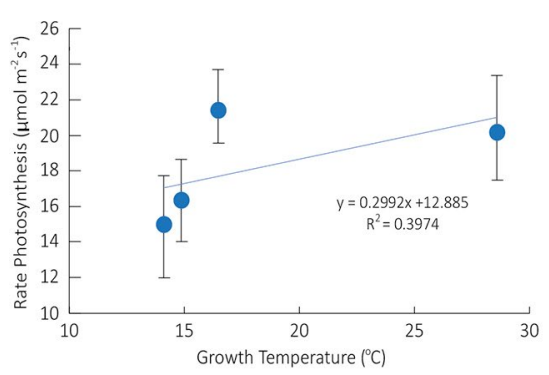

c)

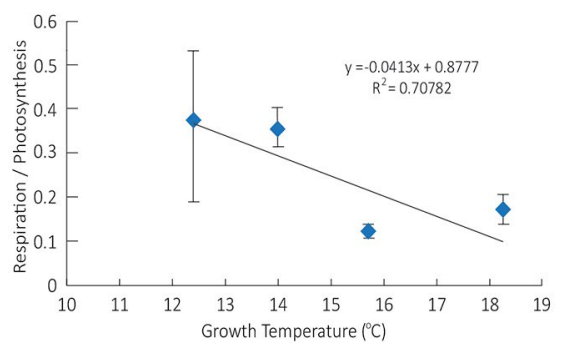

b)

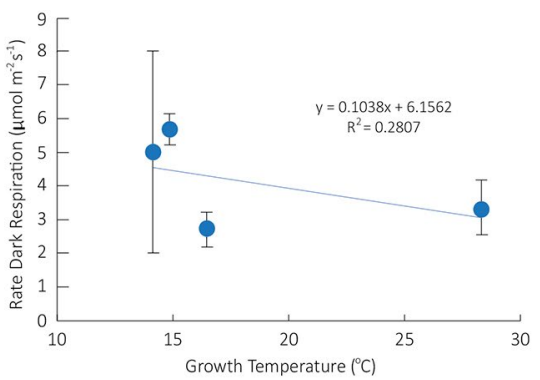

Figure 2: a) Rate of photosynthesis in Eucalyptus pauciflora measured at $25^{\circ} \mathrm{C}$ for the four growth temperatures, b) Rate of respiration in Eucalyptus pauciflora measured at $25^{\circ} \mathrm{C}$ for the four growth temperatures, c) Respiration as a fraction of photosynthesis (respiration/ photosynthesis), measured at the common temperature of $25^{\circ} \mathrm{C}$, for each of the growth temperatures.

Note: Error bars show the standard deviation in the 3 samples from each site.

Source: Author's data.

\section{Discussion}

As expected, temperature decreased with elevation. This allowed comparisons to be made between respiration and photosynthesis for snow gums growing at a range of temperatures. The trend in the photosynthesis results suggests that plants grown in warmer environments photosynthesise at a greater rate at $25^{\circ} \mathrm{C}$ than plants grown in colder environments, and that the rate of photosynthesis at $25^{\circ} \mathrm{C}$ decreases with decreasing growth temperature. This agrees with the proposed hypothesis. The opposite relationship was found for respiration, with plants grown in warmer environments respiring at a slower rate at $25^{\circ} \mathrm{C}$ than plants grown in colder environments, and that respiration rate at $25^{\circ} \mathrm{C}$ increases with decreasing growth temperature. This also agrees with the proposed hypothesis. Taken together, the increased photosynthesis 
and reduced respiration of plants growing at higher temperatures results in the decline of the respiration to photosynthesis ratio as growth temperature increases. This has implications on carbon models as it suggests that as plants acclimate to higher temperatures, the amount of carbon lost by the plant to the atmosphere will be less than that expected if acclimation did not occur.

Of interest, the variability in respiration at the lowest growth temperature was much more than for any of the other growth temperatures. This may be due to the lowest growth temperature corresponding to the highest elevation. One argument is that a more harsh and less homogenous environment on the top of the mountain may have led to more variable respiration rates between individual trees, as other environmental variables apart from temperature may be influencing respiration.

As $25^{\circ} \mathrm{C}$ is much warmer than the average temperatures in the Australian Alps, the conditions under which the samples were tested were most similar to the growth conditions of the warmest sample site. As photosynthesis usually reaches a peak at a temperature close to the growing temperature (Yamori et al. 2013), it is not surprising that photosynthesis was higher in trees growing at temperatures closer to the measured temperature. This means the photosynthetic apparatus has altered to function best in the temperature at which the tree exists. This indicates that photosynthetic acclimation occurs in snow gums.

A similar conclusion can be drawn from the respiration results. As leaves from different sample sites react differently under identical conditions, they must have altered in response to their environment to attain optimal function. Thus, it is likely that snow gums grown at different temperatures respire at a near identical rate when measured at those growth temperatures. This indicates that respiratory acclimation, like photosynthesis, also occurred in snow gums.

Some differences in the growth conditions of the samples could not be controlled and so should be noted when analysing the results of this experiment. The site with growth temperature $16.48^{\circ} \mathrm{C}$ (Information Centre) was a very forested, sheltered area. The trees grew very tall (likely due to the protection from extremes that the surrounding large trees and relatively flat surrounds provided) and thus we were only able to reach leaves on small trees that lacked large, fully mature leaves. At the site with growth temperature $14.88^{\circ} \mathrm{C}$ (Rainbow Lake) every tree was burned from bushfires in 2003 so it was difficult to find large, mature leaves. In both of these cases, we chose the most mature-looking leaves we could find. 
The trees at Charlotte Pass $\left(14.12^{\circ} \mathrm{C}\right)$ were all in flower or about to flower. This was not the case in trees in other locations. Therefore, these trees were investing energy into making flowers and so it is likely that the rate that was attained for dark respiration was not actually the rate of dark respiration due to investing energy into reproduction.

An indication of the divergence in environmental conditions, other than temperature, that could affect physiological processes between the four sites is evident in the LMA results. LMA usually increases in cold and hot environments (Poorter et al. 2009). An increase in LMA with increasing elevation was expected, as the cold and harsh environment (snow covered in winter) of the mountain top would induce thicker, more robust leaves to withstand those conditions. However, there was no clear trend between LMA and temperature/elevation. Therefore, local environmental conditions, rather than temperature gradient associated with the elevation gradient, were impacting on leaf morphology and presumably also impacting on photosynthesis and respiration rates.

There has been some evidence in the literature to suggest that acclimation of plant respiration to temperature does not occur (Dewar et al. 1999; Dillaway and Kruger 2011; Liang et al. 2013). Because of this, it was predicted that the increased temperatures, inevitable due to climate change, would result in an increase in the rate of plant respiration and thus an increase in $\mathrm{CO}_{2}$ release, and this would then speed up climate change further, which would result in more $\mathrm{CO}_{2}$ release and the cycle would go on. This idea was incorporated into the climate change models.

Most evidence now is suggesting thermal acclimation of respiration and photosynthesis does occur (Atkin et al. 2000; Bunce 2007; King et al. 2006) and this study supports that evidence. It suggests that future atmospheric $\mathrm{CO}_{2}$ levels may not be as high as previously thought and this idea is now being incorporated into current climate change models. The accuracy of these models is improving, and this allows society to rely more heavily on the models for future planning.

Recent evidence is suggesting that other environmental factors have a much greater effect on rates of photosynthesis and respiration in plants than temperature, including leaf nitrogen content, water availability and levels of carbohydrates in the plants (Dillaway and Kruger 2011; Lewis et al. 2011). Further research into the effects of these factors as well as how predicted environmental changes will affect these factors would 
also improve the predictions of the levels of $\mathrm{CO}_{2}$ and temperature in the future. More accurate knowledge on this would allow for more accurate climate change models.

What controls respiration and photosynthesis physiologically is still widely unknown (Gonzalez-Meler et al. 2004) and, ultimately, having a complete understanding of how these processes work would give a greater insight into how plants are likely to respond to the pressures of the future climate.

\section{Acknowledgements}

The authors thank Owen Atkin, Andrew Scafaro and Nur Abdul Bahar for their guidance and assistance.

\section{References}

Amthor J (2000) The McCree-de Wit-Penning de Vries-Thornley respiration paradigms: 30 years later. Annals of Botany 86: 1-20. doi. org/10.1006/anbo.2000.1175

Atkin I, Holly C, Ball M (2000) Acclimation of snow gum (Eucalyptus pauciflora) leaf respiration to seasonal and diurnal variation in temperature: The importance of changes in the capacity and temperature sensitivity of respiration. Plant, Cell \& Environment 23: 15-26. doi.org/10.1046/j.1365-3040.2000.00511.x

Atkin O, Tjoelker M (2003) Thermal acclimation and the dynamic response of plant respiration to temperature. Trends in Plant Science 8: 343-51. doi.org/10.1016/S1360-1385(03)00136-5

Bunce J (2007) Direct and acclimatory responses of dark respiration and translocation to temperature. Annals of Botany 11: 67-73. doi. org/10.1093/aob/mcm071

Cooper GM (2000) Metabolic energy. In: The Cell: A Molecular Approach, 2nd edn. ASM Press, Washington, DC; Sinauer Associates, Sunderland, MA. doi.org/10.1007/s004420050381

Curtis P, Wang X (1998) A meta-analysis of elevated $\mathrm{CO}_{2}$ effects on woody plant mass, form, and physiology. Oecologia 113: 299-313. 
Dewar R, Medlyn B, Mcmurtrie R (1999) Acclimation of the respiration/photosynthesis ratio to temperature: Insights from a model. Global Change Biology 5: 615-22. doi.org/10.1046/j.13652486.1999.00253.x

Dillaway D, Kruger E (2011) Leaf respiratory acclimation to climate: Comparisons among boreal and temperate tree species along a latitudinal transect. Tree Physiology 31: 1114-27. doi.org/10.1093/ treephys/tpr097

Gonzalez-Meler M, Taneva L, Trueman R (2004) Plant respiration and elevated atmospheric $\mathrm{CO}_{2}$ concentration: Cellular responses and global significance. Annals of Botany 94: 647-56. doi.org/10.1093/aob/ mch189

Hansen M, Stehman S, Potapov P (2010) Quantification of global gross forest cover loss. Proceedings of the National Academy of Sciences of the United States of America 107: 8650-5. doi.org/10.1073/ pnas.0912668107

King A, Gunderson C, Post W, Weston D, Wulischleger S (2006) Plant respiration in a warmer world. Science 312: 536-7. doi.org/10.1126/ science. 1114166

Lewis J, Phillips N, Logan B, Hricko C, Tissue D (2011) Leaf photosynthesis, respiration and stomatal conductance in six Eucalyptus species native to mesic and xeric environments growing in a common garden. Tree Physiology 31: 997-1006. doi.org/10.1093/treephys/ tpr087

Liang J, Xia J, Liu L, Wan S (2013) Global patterns of the response of leaf-level photosynthesis and respiration in terrestrial plants to experimental warming. Journal of Plant Ecology 6: 437-47. doi. org/10.1093/jpe/rtt003

Ow L, Whitehead D, Walcroft A, Turnbull M (2008) Thermal acclimation of respiration but not photosynthesis in Pinus radiata. Functional Plant Biology 35: 448-61. doi.org/10.1071/FP08104

Poorter H, Niinemets U, Poorter L, Wright I, Villar R (2009) Causes and consequences of variation in leaf mass per area (LMA): A metaanalysis. New Phytologist 182: 565-88. doi.org/10.1111/j.14698137.2009.02830.x 
Slayter R, Morrow P (1977) Altitudinal variation in the photosynthetic characteristics of snow gum, Eucalyptus pauciflora Sieb. Ex Spreng. I. Seasonal changes under field conditions in the Snowy Mountains area of south-eastern Australia. Australian Journal of Botany 25: 1-20. doi.org/10.1071/BT9770001

Stillman J (2003) Acclimation capacity underlies susceptibility to climate change. Science 301: 65. doi.org/10.1126/science.1083073

Yamori W, Hikosaka K, Way D (2013) Temperature response of photosynthesis in C3, C4, and CAM plants: Temperature acclimation and temperature adaptation. Photosynthesis Research 119: 101-17. doi. org/10.1007/s11120-013-9874-6 
This text is taken from Researching functional ecology in Kosciuszko National Park, edited by Hannah Zurcher, Chia Ming-Dao, Michael Whitehead and Adrienne Nicotra, published 2017 by ANU eView, The Australian National University, Canberra, Australia. dx.doi.org/10.22459/RFEKNP.11.2017.05 